\title{
Psoriasis and systemic lupus erythematosus in children - literature review based on case report
}

\author{
Izabela Dybowska-Gołota ${ }^{1}$, Agnieszka Owczarczyk-Saczonek², \\ Magdalena Krajewska-Włodarczyk ${ }^{3,4}$, Zbigniew Żuber ${ }^{5,6}$ \\ ${ }^{1} 4^{\text {th }}$ Department of Pediatric Rheumatology and Endocrinology, Regional Specialized Children's Hospital in Olsztyn, Poland \\ ${ }^{2}$ Department and Clinic of Dermatology, Sexually Transmitted Diseases and Clinical Immunology, University of Warmia and Mazury, \\ Olsztyn, Poland \\ ${ }^{3}$ Department of Rheumatology, Municipal Hospital Complex, Olsztyn, Poland \\ ${ }^{4}$ Department of Internal Medicine, School of Medicine, Collegium Medicum, University of Warmia and Mazury, Olsztyn, Poland \\ ${ }^{5}$ Department of Pediatrics, Faculty of Medicine and Health Sciences, Andrzej Frycz Modrzewski Krakow University, Poland \\ ${ }^{6}$ Ward for Older Children with Neurology and Rheumatology Subdivision, St. Louis Regional Specialized Children's Hospital \\ in Krakow, Poland
}

\begin{abstract}
Immune-mediated inflammatory diseases are a group of diseases characterized by generalized inflammation that results from immune dysregulation, especially involving the mechanisms of acquired immunity. These diseases may be familial, showing that genetic factors play an important role in their development. Additionally, the occurrence of one disease makes a patient prone to other diseases. However, the coexistence of systemic lupus erythematosus (SLE) and psoriasis (PS) is very rare due to their distinct genetic determinants and mechanisms of pathogenesis. Treatment is also challenging, as medications used to treat one condition exacerbate or even trigger the symptoms of the other. This paper presents the case of a Ps patient with a family history of autoimmune diseases, who developed systemic lupus erythematosus during puberty, as well as a discussion on the coexistence of SLE and PS in developmental age based on available literature searching for PubMed database and American College of Rheumatology and European League Against Rheumatism abstracts particularly in this subject.
\end{abstract}

Key words: psoriasis, systemic lupus erythematosus, immune-mediated inflammatory diseases.

\section{Introduction}

Both psoriasis (Ps) and systemic lupus erythematosus (SLE) belong to a group of immune-mediated inflammatory diseases (IMIDS), but their coexistence is very rare $[1,2]$. This may stem from their distinct genetic determinants and pathogenesis. The pathogenesis of these autoimmune diseases involves the activation of different T cell subtypes: mainly Th1 cells in the case of Ps, while SLE is caused by Th2 cell activation. Therefore, cases of patients previously diagnosed with Ps who develop SLE with no association with drugs used as part of treatment are incidental [3-5]. There are reports of cases in which patients develop lupus as a result of treatment for Ps, primarily using biologics [6-8].

\section{Objective and methods}

The objective of this article was to present the clinical problem of PS and SLE coexistence.

Methods: case study presentation as a basis for discussion, literature search of PubMed database and American College of Rheumatology (ACR) and European League Against Rheumatism (EULAR) abstracts particularly in the subject of coexistence of SLE and Ps in developmental age using the combination of words "systemic

Address for correspondence:

Izabela Dybowska-Gołota, $4^{\text {th }}$ Department of Pediatric Rheumatology and Endocrinology, Regional Specialized Children's Hospital in Olsztyn, 18 Żołnierska St., 10-561 Olsztyn, Poland, e-mail: izabelago@vp.pl

Submitted: 21.12.2019; Accepted: 28.01.2020 
lupus erythematosus" and "psoriasis", "children", "pediatric population"; discussion of the problem based on the clinical case and cited articles.

\section{Results}

\section{Case presentation}

A 14-year-old female patient with a history of mild Ps was referred to hospital with anemia. On admission, the girl complained of joint pain and morning stiffness lasting up to 30 minutes; no swollen joints were observed. A butterfly shaped, pale-pink rash had been present for several days on the patient's cheeks and nasal bridge. The patient suffered from recurrent, painless oral ulcers.

The girl was delivered at 32 weeks gestation, in the second childbirth, of her mother's $7^{\text {th }}$ pregnancy. She developed Ps at age 3. Skin lesions were present on the scalp, behind the ears, and on the elbows and hands. The use of topical preparations recommended by the dermatologist yielded good results and no systemic drugs were required.

There is a family history of thyroiditis and recurrent fetal loss in the child's mother. According to the mother, the reasons for five miscarriages, at 12 to 25 weeks gestation, have not been established. The maternal grandmother has systemic lupus erythematosus, and the paternal grandmother had sclerosis multiplex (SM). The patient's older sister was diagnosed with a demyelinating disease.

On admission, the patient was in overall fairly good condition, weak, apathetic. Physical examination revealed a pale-pink, flat rash on the cheeks and nasal bridge, yellowish sclera and slight muscle weakness. Subcutaneous tissue was excessively developed, and the girl was overweight.

Laboratory tests revealed megaloblastic hemolytic anemia with positive Coombs test results and the presence of cold IgM and warm IgG autoantibodies of unknown specificity as well as complement C3d on red blood cells and in serum. Immunoglobulin $\mathrm{M}$ and ferritin levels were high and the levels of complement components $C 3 C$ and $C 4$ were very low. Titers of antinuclear antibodies (ANA), anticardiolipin IgM antibodies (ACA-IgM) and anti- $\beta$-2-glycoprotein 1 IgM (aß-2-GP I-IgM) antibodies were high. Lupus anticoagulant (LA) was present.

Inflammatory marker levels as well as leukocyte and platelet counts were normal. No abnormalities were found in coagulation factors, the activity of liver and muscle enzymes, kidney function, immunoglobulin $A$ and $G$ levels, general urine test results and the 24-hour urine protein test results.

The patient tested negative for HLA-B27 and HLACw6 antigens, anti-thyroid peroxidase antibodies (TPO), antithyroglobulin antibodies (TgAb), tTG IgA and rheumatoid factor (RF). Infections such as HBV, HCV, HIV, EBV and Borrelia were excluded.

The results of magnetic resonance imaging (MRI) of the head, electromyography (EMG), nailfold capillaroscopy, echocardiography and electrocardiography were in the normal range. The chest radiograph as well as ultrasound imaging of the abdomen, thyroid and tender joints displayed no abnormalities.

The results of tests performed as part of specialist consultations with the neurologist and ophthalmologist revealed no abnormalities. The patient met the 2012 SLICC criteria for SLE classification validated for children [4].

Initially, treatment with hydroxychloroquine ( $\mathrm{HQ}$ ) and acetylsalicylic acid (ASA) was recommended. Glucocorticosteroid (GCS) therapy was considered, but due to the child's good condition and extended period (at least several weeks) of mild anemia, treatment was not intensified. The patient was feeling well after treatment was initiated and the results of follow-up tests indicated that the blood count was gradually returning to normal levels.

After three months, follow-up was carried out. The patient reported sporadic joint pain. Skin and mucosal symptoms of SLE and oral ulcers decreased or appeared occasionally. However, the malar rash persisted. Psoriatic skin changes became more frequent, but were mild and topical treatment was sufficient. Laboratory testing did not reveal anemia, but the Coombs test remained positive and cold IgM and warm IgG autoantibodies as well as complement C3d were still present. Complement component $\mathrm{C} 3 \mathrm{c}$ and ferritin levels returned to the normal range, while complement component $C 4$ remained very low, serum IgM and LA levels were high, and ANA remained in a significantly elevated titer. There were no other abnormalities in blood tests. The clinical symptoms and laboratory test results suggested SLE. Treatment was maintained due to the patient's good clinical condition and improved test results, despite periodic exacerbations in psoriatic lesions.

After one year, the blood count was normal, complement component $C 4$ levels remained low and the titers of ANA, LA, serum a $\beta$-2-GP I-IgM antibodies and ACA IgM antibodies remained high. The results of the remaining follow-up tests were in the normal range. The relevant results from baseline to one year of treatment are presented in Table I.

\section{Discussion}

There are differences in the worldwide prevalence of autoimmune diseases such as SLE and Ps. The prevalence of SLE varies with gender, age and ethnicity and 
Table I. Laboratory test results

\begin{tabular}{|c|c|c|c|}
\hline Parameter & Baseline & After 3 months & After one year \\
\hline $\begin{array}{l}\text { Erythrocytes }\left(\times 10^{12} / 1\right) \\
(3.5-5.0)\end{array}$ & 2.8 & 4.4 & 4.8 \\
\hline $\begin{array}{l}\text { Hemoglobin }(g / d l) \\
(11.2-15.2)\end{array}$ & 9.9 & 13.9 & 15.5 \\
\hline $\begin{array}{l}\text { Hematocrit (\%) } \\
(33.0-43.5)\end{array}$ & 28.4 & 40.7 & 44.4 \\
\hline $\begin{array}{l}\text { Reticulocytes (\%) } \\
(0.6-2.6)\end{array}$ & 7.19 & 1.78 & - \\
\hline $\begin{array}{l}\text { Total bilirubin }(\mathrm{mg} / \mathrm{dl}) \\
(<1.00)\end{array}$ & 1.6 & 0.63 & 0.4 \\
\hline $\begin{array}{l}\mathrm{LDH}-\mathrm{I}(\mathrm{U} / \mathrm{l}) \\
(<279)\end{array}$ & 311 & 157 & 170 \\
\hline $\begin{array}{l}\text { Ferritin }(\mathrm{ng} / \mathrm{ml}) \\
(13.00-68.00)\end{array}$ & 200.13 & 43.33 & 32.64 \\
\hline $\begin{array}{l}\text { Complement C4 (mg/dl) } \\
(10.0-40.0)\end{array}$ & $<0.6$ & $<0.6$ & $<0.6$ \\
\hline $\begin{array}{l}\text { Complement C3c (mg/dl) } \\
(77-125)\end{array}$ & $<30$ & 79.1 & 85.1 \\
\hline $\begin{array}{l}\text { Immunoglobulin M (mg/dl) } \\
\text { (15-188) }\end{array}$ & 910 & 616 & 531 \\
\hline $\begin{array}{l}\text { ANA } \\
\text { immunofluorescence on HEp-2 cells } \\
\text { (pattern, titer) }\end{array}$ & $\begin{array}{c}\text { speckled and homogeneous } 1: 3200 \\
\text { nuclear membrane } 1: 3200 \\
\text { nuclear dots } 1: 3200 \\
\text { mitochondrial } 1: 3200\end{array}$ & - & $\begin{array}{c}\text { speckled } 1: 1000 \\
\text { homogeneous } 1: 320 \\
\text { nuclear membrane } 1: 1000 \\
\text { nuclear dots } 1: 320 \\
\text { mitochondrial } 1: 3200\end{array}$ \\
\hline $\begin{array}{l}\text { ENA } \\
\text { (immunoblot) }\end{array}$ & $\begin{array}{c}\text { anti-nucleosome } \mathrm{Ab}+ \\
\text { anti-histone } \mathrm{Ab}+++ \\
\text { anti-AMA-M2 Ab+ }\end{array}$ & - & $\begin{array}{l}\text { anti-Sm (+) } \\
\text { anti-Pm-Scl + }\end{array}$ \\
\hline $\begin{array}{l}\text { Anticardiolipin antibodies }(\mathrm{U} / \mathrm{ml}) \\
\text { (> } 12 \text { positive) }\end{array}$ & $\begin{array}{l}\lg M>120 \\
\operatorname{lgG} 7.4\end{array}$ & - & $\begin{array}{c}>120 \\
-\end{array}$ \\
\hline $\begin{array}{l}\text { Anti- } \beta \text {-2-glycoprotein I antibodies } \\
(\mathrm{U} / \mathrm{ml})(>20 \text { positive })\end{array}$ & $\begin{array}{l}\lg M>200 \\
\lg 8.15\end{array}$ & - & $\begin{aligned} \lg M & >200 \\
& -\end{aligned}$ \\
\hline
\end{tabular}

ranges from 2 to 660 per 100,000 [3]. Juvenile SLE is rare, with a prevalence of 3.3-8.8 per 100,000 children. It often follows a more aggressive course than adult-onset SLE, with relapse and remission episodes during puberty leading to greater morbidity and mortality [4].

The prevalence of Ps in the global adult population ranges from 0.51 to $11.43 \%$, and from 0 to $1.3 \%$ in children [5]. One-third of Ps cases begin during childhood, with the same clinical subtypes as in adults, but the lesions may have a different distribution and morphology. In juvenile Ps, precipitating factors, including infections, medications and stress, are more common than in adult-onset disease [9].

In 2002, the concept of IMIDs emerged. The etiology of these diseases has not been fully understood; the clinical manifestations clearly vary but patients respond to drugs that affect the immune system. This pattern was especially apparent during anti-TNF $\alpha$ treatment $[1,10,11]$ and led to the conclusion that IMIDs share common pathogenic mechanisms.

Pathogenesis consists in generalized inflammation caused by immune dysfunction. An abnormal response to one's own antigens leads to the activation of autoreactive $T$ lymphocytes, $B$ lymphocytes, the production of inflammatory cytokines and specific autoantibodies, without any ongoing infection or other apparent reason $[1,10-13]$.

It is believed that the inflammatory cascade is initiated with the activation of CD4+ T cells, generating the production of several inflammatory cytokines, including TNF- $\alpha$, which later activate CD8+ T cells, B cells and other effector cells. Activated B cells produce autoantibodies, but also activate $T$ cells to synthesize cytokines and other signaling proteins $[10,13]$. 
The prevalence of IMIDs is estimated at about $5 \%$ of the general population, with most patients between the ages of 20 and 50. IMIDs include many diseases that affect systems as well as individual organs [1]. Table ॥ shows the most common and significant IMIDs that coexist with rheumatic diseases [1].

Autoimmune diseases are familial, which proves that genetic factors play an important role in their development $[1,2,10]$. Moreover, patients with one autoimmune disease show a predisposition fovr the development of other autoimmune diseases. For example, psoriatic arthritis (PSA), inflammatory bowel disease (IBD), type 1 diabetes and uveitis are more common in Ps patients [14-16].

Psoriasis in particular may be accompanied by arthritis, IBD and autoimmune uveitis, which lead to the development of spondyloarthropathies, mainly PsA. In children, many IMIDs take the form of juvenile idiopathic arthritis (JIA), often accompanied by uveitis or IBD $[10-12,16]$.

An analysis of Danish records revealed that Ps patients had at least one additional autoimmune disease significantly more frequently and moreover, children with Ps were at a much higher risk of developing multiple autoimmune diseases which was not observed in adults. In comparison with the control group, PsA, autoimmune thyroiditis and IBD were noticeably more frequent in children with Ps, while a significant increase in type 1 diabetes or celiac disease was not observed [17].

The familial occurrence of IMIDs stems not only from a common genetic predisposition but possibly also from the mutual mother-infant interactions in the perinatal period. The mother's autoantibodies, immune complexes and inflammatory mediators that enter fetal circulation may program the child's immune system, impairing its functioning in the future. This mechanism may explain the increased risk of autoimmune disease development in the child of a mother with SLE [18].

Canadian researchers who investigated children born in 1989-2009 to mothers with SLE $(n=719)$ found that they were at a greater risk of autoimmune disease, more often non-rheumatic than rheumatic, than children in the control group. Crohn's disease, type 1 diabetes and Ps were the most prevalent. The prevalence of rheumatic IMIDs was comparable in both groups. The authors cite other studies in which the children of mothers with SLE most commonly developed IBD and autoimmune thyroiditis, while the children of mothers with SLE and anti-Lo and/or anti-Ra antibodies had the highest risk of developing JIA and non-rheumatic autoimmune diseases, such as autoimmune thyroiditis, Ps, iritis and type 1 diabetes. At the same time, it is worth noting that autoimmune diseases in children born to mothers with
SLE are rare and the vast majority of offspring are free from any autoimmune diseases [18].

The coexistence of PS and SLE is very rare and there are relatively few reports of such patients in the literature [19]. Most papers analyze individual cases or small groups of patients and cross-sectional studies are lacking. As one might expect, since SLE is more prevalent in women, the coexistence of Ps and SLE affects women more often as well [19, 20].

Table II. Immune-mediated inflammatory diseases [acc. 1]

\begin{tabular}{|c|}
\hline Immune-mediated inflammatory diseases (IMIDs) \\
\hline Autoimmune rheumatic diseases \\
\hline Rheumatoid arthritis (RA) \\
\hline Juvenile idiopathic arthritis (JIA) \\
\hline Spondyloarthropathies \\
\hline Ankylosing spondylitis \\
\hline Psoriatic arthritis \\
\hline $\begin{array}{l}\text { Arthropathies coexisting with inflammatory bowe } \\
\text { disease }\end{array}$ \\
\hline Enthesitis-related arthritis (ERA) \\
\hline Systemic connective tissue diseases \\
\hline Systemic lupus erythematosus (SLE) \\
\hline Sjögren's syndrome \\
\hline Poly- and dermatomyositis \\
\hline Systemic vasculitis (SV) \\
\hline Systemic sclerosis \\
\hline Metabolic and endocrine syndromes \\
\hline Type 1 diabetes \\
\hline Inflammatory bowel disease (IBD) \\
\hline Autoimmune thyroiditis \\
\hline Skin diseases \\
\hline Psoriasis (Ps) \\
\hline Hidradenitis suppurativa \\
\hline Vitiligo \\
\hline Alopecia areata \\
\hline Nervous system diseases \\
\hline Myasthenia gravis \\
\hline Sclerosis multiplex (SM) \\
\hline Neuromyelitis optica (Devic's syndrome) (NMO) \\
\hline Eye diseases \\
\hline Autoimmune uveitis \\
\hline Glaucoma \\
\hline Others \\
\hline Idiopathic thrombocytopenia \\
\hline Sarcoidosis \\
\hline
\end{tabular}


According to observations of large groups of patients with autoimmune diseases, lupus occurs in $0.69 \%$ of Ps patients, while Ps occurs in $1.1 \%$ of patients who had previously been diagnosed with lupus, which is rarer than in the general population $[6,19,21]$.

In 2013, Shadakshari et al. [22] presented the results of research on 455 SLE patients, showing that $5.1 \%$ $(n=23)$ had Ps and most of these $(n=20,4.5 \%)$ had PsA. The authors concluded that the prevalence of PsA, not Ps, is increased in patients with SLE. A study conducted in Canada yielded similar results, whereby $3.46 \%$ of SLE patients $(n=832)$ were additionally diagnosed with PS [2]. However, these studies involved adult patients.

One of the first reports of cases of coexistent Ps and SLE was published in 1936 [23]. Few such cases have been published so far and it cannot be clearly determined which of these diseases occurs earlier. It is also worth mentioning that skin lesions occur in both of these autoimmune diseases and it is conceivable that in a certain percentage of cases, the initial diagnosis is incorrect.

There are both HLA and other genes that predispose to the development of SLE. Lupus erythematosus susceptibility is associated with HLA class II gene polymorphisms, namely HLA-DRB1, -DR3, -DR4, -DR9, -DR11 and -DR15 [24, 25]. Other risk factors for SLE include polymorphisms of genes responsible for DNA degradation (TREX, DNase I), type I interferon activation by Toll-like receptors (IRF5/7, STAT4, TLR7/8, IRAK1, ACP5, SPP1), signaling by $T$ lymphocytes (PTPN22, TNFSF4), B lymphocytes (BLK, BANK1) or genes that trigger intracellular signaling pathways (TNFAIP3, TNIP1, PRKCB). In individuals with a genetic predisposition, environmental factors activate autoimmune reactions and lead to the development of inflammation [24, 26, 27].

The clinical symptoms of SLE are associated with the presence of pathogenic autoantibodies. These are produced as a result of polyclonal $B$ cell activation by autoantigens, and activation by active Th2 cells and the IL-6 and IL-10 that these produce [6, 28].

The genes that predispose to the development of Ps include HLA-B27, HLA-Cw6, HLA-DR7 and HLA-DRB1 [15, 29-32], as well as polymorphisms of many non-HLA genes, such as PSORS 3 on chromosome $4 q$ or the $4 q 27$, $16 q 12$ and 1 p13 loci, as well as the $5 q 31$ locus, which is associated with Ps, RA, asthma and atopic dermatitis [30]. Epigenetic mechanisms, DNA hypermethylation, histone $\mathrm{H} 4$ hypoacetylation and abnormal microRNA expression lead to T cell hyperactivation. Th1 and Th17 activation and the effects of IFN- $\gamma$, IL-2, IL-12, IL-17 and $\mathrm{IL}-23$ produced by these cells play a crucial role in the pathogenesis of Ps $[6,13,20,29,32]$. The function of regulatory T cells (Tregs), which are responsible for destroying autoreactive lymphocytes, is also compromised [29].
Despite the discrepancies, both disease entities do share some features. In terms of genetic predisposition, these include the above-mentioned HLA-DRB1 and the polymorphisms of several loci outside of the major histocompatibility complex, such as 16q12, 1p13 and 4q27 [30], especially in the Chinese population, s8016947 and rs4649203 [6].

In terms of the development of inflammation, B lymphocytes and Th2 lymphocytes play a major role in SLE, while in Ps these are predominantly Th1 lymphocytes. What is common for both disease entities is only the increased number of Th17 lymphocytes and increased serum IL-7 and IL-23 levels [20].

In an analysis of the clinical picture, Shadakshari et al. [22] note that the occurrence of a malar rash, photosensitivity and arthritis was increased while antiphospholipid antibodies were less common in SLE patients with coexisting Ps and PSA. The authors found no significant link between Ps or PsA and seizures, psychosis, oral ulcers, serositis, proteinuria, anemia, leukopenia, thrombocytopenia, hemolytic anemia, the presence of anti-Sm or anti-DNA antibodies [22].

Tselios et al. [2] report that in SLE patients with Ps, low complement levels and/or increased anti-dsDNA antibody levels were observed less frequently, and ACPA were mostly absent (present in 0\% of SLE patients with Ps and 6.1\% of SLE patients without PS). Antiphospholipid antibodies, rheumatoid factor (RF) and other anti-ENA antibodies did not differ significantly between the two groups [2].

The similarities and differences between the two diseases are presented in Table III.

The choice of treatment in patients with coexistent SLE and Ps is challenging. One of the main treatment methods for Ps, UV radiation, may induce and/or exacerbate not only skin lesions but also the course of SLE [33]. This is more common in patients with previously reported photosensitivity [21]. Tests that would be useful to determine patients at risk include ANA, anti-dsDNA, anti-Ro and skin biopsy for direct immunofluorescence $[19,20]$.

In turn, antimalarial drugs, which are fundamental in SLE treatment, may induce or exacerbate psoriatic skin lesions [6-8] or even be linked to the induction of Ps [34]. The treatment of severe cases of Ps with anti-TNF- $\alpha$ is associated with the risk of drug-induced lupus (diSLE) $[7,35,36]$.

However, the development of SLE as a result of treatment with TNF- $\alpha$ inhibitors is relatively rare $0.19-0.22 \%$ for infliximab, $0.18 \%$ for etanercept and $0.10 \%$ for adalimumab - and the autoantibodies induced are typically IgM and are not pathogenic [40]. Varada et al. [37] analyzed 96 patients with Ps and DLE, SCLE or SLE (including 85 with SLE). Among 20 patients receiving TNF- $\alpha$ inhibitors, one case of lupus exacerbation was 
observed (5\%), which represents an exacerbation rate of $0.92 \%$ per patient per year of TNF inhibitor use [37].

It should be borne in mind that GCS used in the treatment of SLE may exacerbate Ps and cause a pustular form of this disease that otherwise mainly affects the skin $[6,8,35]$. Methotrexate (MTX) may be a good therapeutic option as it is recommended for both skin lesions and arthritis in Ps and skin and/or joint involvement in the course of SLE [35].

The case that we present here, together with the family medical history, is an interesting example confirming the familial occurrence of IMIDs and their potential coexistence. In Ps patients, drug-induced lupus is a possible complication, but the patient whose case is presented here did not take systemic drugs that could cause such complications. Tselios et al. [2] made similar observations in a group of 63 adult Canadian patients with Ps and SLE. The authors concluded that Ps had no impact on SLE activity and topical treatment of PS was sufficient in the majority of patients.

In the present case, despite the potential risk of Ps exacerbation, an antimalarial drug was initially used, and the principles of treatment were also discussed with the patient and her parents, including the reduction of exposure to UV radiation.

In many cases, hemolytic anemia requires the use of GCS, but according to the literature, the use of GCS in combination with $\mathrm{HQ}$ carries a high risk of severe Ps exacerbation $[6,8,35]$. The condition of the patient in question improved during the initial treatment. There-

Table III. Comparison of main features of psoriasis and systemic lupus erythematosus

\begin{tabular}{|c|c|}
\hline Psoriasis & Lupus erythematosus \\
\hline \multicolumn{2}{|l|}{ Skin lesions } \\
\hline $\begin{array}{l}\text { Red plaques of skin that flake or develop scales } \\
\text { The appearance of thick, white patches of skin called plaques } \\
\text { on the elbows, knees, and other areas of the body, patches of } \\
\text { skin that itch, crack, or bleed } \\
\text { Shiny, red lesions in folds of skin } \\
\text { Small red dots on the trunk, in the case of guttate psoriasis }\end{array}$ & $\begin{array}{l}\text { A butterfly-shaped rash on the face } \\
\text { Joint pain } \\
\text { Body rashes, particularly after sun exposure } \\
\text { Fingers or toes turning blue or white on exposure } \\
\text { to the cold }\end{array}$ \\
\hline \multicolumn{2}{|l|}{ UV } \\
\hline UV radiation - improves and inhibits lesions & $\begin{array}{l}\text { UV photosensitivity - UV exposure worsening course } \\
\text { of the disease }\end{array}$ \\
\hline \multicolumn{2}{|l|}{ Genetic predisposition } \\
\hline HLA-B27, HLA-Cw6, HLA-DR7 and HLA-DRB1 & HLA-DRB1, -DR3, -DR4, -DR9, -DR11 and -DR15 \\
\hline \multicolumn{2}{|l|}{ Musculoskeletal symptoms } \\
\hline $\begin{array}{l}\text { Arthralgia } \\
\text { Arthritis (if psoriatic arthritis develops) }\end{array}$ & $\begin{array}{l}\text { Arthralgia, myalgia } \\
\text { Jaccoud's arthropathy, nonerosive arthritis }\end{array}$ \\
\hline \multicolumn{2}{|l|}{ General symptoms } \\
\hline Not occur & Fever, malaise, fatigue, weight loss \\
\hline \multicolumn{2}{|l|}{ Laboratory tests } \\
\hline Usually normal & $\begin{array}{l}\text { Hemolytic anemia, Coombs positivity, thrombocytopenia, } \\
\text { leucopenia, lymphopenia, increased ESR, low complement } \\
\mathrm{C} 3, \mathrm{C} 4, \mathrm{CH} 50 \text {, abnormal titer of ANA, antibody anti-dsDNA, } \\
\text { anti-Sm, positive test results for anti-phospholipid antibody }\end{array}$ \\
\hline \multicolumn{2}{|l|}{ Skin histopathology } \\
\hline $\begin{array}{l}\text { Epidermal acanthosis, hyperkeratosis and parakeratosis } \\
\text { (cell nuclei present) in the cornified layer. In the dermis, } \\
\text { dilated and contorted blood vessels reach into the tips of } \\
\text { the dermal papillae. An inflammatory infiltrate containing } \\
\text { T-lymphocytes, macrophages, mast cells, and neutrophilic } \\
\text { granulocytes within the dermis and epidermis [28] }\end{array}$ & $\begin{array}{l}\text { Mild hyperkeratosis, atrophy of epidermis with effaced } \\
\text { of ridge pattern, sometimes parakeratosis. Hair follicles } \\
\text { are often unaffected or slight keratin plugging. In dermis } \\
\text { lymphocytic exocytosis may be conspicuous and satellite } \\
\text { cell necrosis. The inflammatory cell infiltrate is mild, } \\
\text { superficially and perivascular located [29] }\end{array}$ \\
\hline \multicolumn{2}{|l|}{ Skin immunofluorescence } \\
\hline Not characteristic & $\begin{array}{l}\text { Deposition of immunoglobulins (IgG, IgM, IgA) and } \\
\text { complement components in the skin, demonstrable as } \\
\text { a linear band at the basement membrane zone by direct } \\
\text { immunofluorescence (lupus band test, LBT) [29] }\end{array}$ \\
\hline
\end{tabular}


fore, and taking into consideration the short duration of hemolytic anemia, GCS were not administered at this stage of the disease. As a result of the implemented treatment regimen, the patient's condition was assessed as good and follow-up tests showed a gradual return to normal blood count values and other parameters associated with hemolytic anemia.

In the present case, the decision regarding treatment resulted from the inclusion of both coexisting autoimmune diseases.

Varada et al. [37] showed that in the case of Ps and SLE coexistence and the need for aggressive Ps treatment with TNF- $\alpha$ inhibitors, SLE flare was rare. The authors also suggested that treatment with biologics with other mechanisms of action, such as ustekinumab or abatacept, may be a good treatment option for patients with PS and SLE. These observations involved adult patients only.

In the patient described SLE activity was decreased in both clinical and immunological terms. Psoriatic skin lesions did not exacerbate and treatment was only topical. The patient will continue to be monitored by a rheumatologist and dermatologist - such cooperation is of particular importance in cases where treatment may have a negative impact on the coexisting disease. Also, the assessment of skin changes by a dermatologist in the case of their exacerbation is very useful and may have a significant impact on the treatment of both autoimmune diseases.

\section{Conclusions}

In this paper based on a case report we discuss the rare but relevant issue of PS and SLE as comorbidities. The reviewed literature on this topic most often presents studies or case reports concerning adult patients, while children in this clinical situation have not been well described. Cross-sectional studies focus mainly on Ps and IMIDs other than SLE [17], and the available publications concerning PS with SLE involve smaller groups of patients, so case reports can be a valuable source for comparative analyses and knowledge sharing.

The authors declare no conflict of interest.

\section{References}

1. Majdan M. Immune-Mediated Inflammatory Diseases and accompanying comorbidities. Wiad Lek 2016; 69: 611-615.

2.Tselios K, Yap KS, Pakchotanon R, et al. Psoriasis in systemic lupus erythematosus: a single-center experience. Clin Rheumatol 2017; 36: 879-884, DOI: 10.1007/s10067-017-3566-0.

3. Rees F, Doherty M, Grainge MJ, et al. The worldwide incidence and prevalence of systemic lupus erythematosus: a systemat- ic review of epidemiological studies. Rheumatology (Oxford) 2017; 56: 1945-1961, DOI: 10.1093/rheumatology/kex260.

4. Levy DM, Kamphuis S. Systemic lupus erythematosus in children and adolescents. Pediatr Clin North Am 2012; 59: 345-364, DOI: 10.1016/j.pcl.2012.03.007.

5. Michalek IM, Loring B, John SM. A systematic review of worldwide epidemiology of psoriasis. J Eur Acad Dermatol Venereol 2017; 31: 205-212, DOI: 10.1111/jdv.13854.

6. Tan JAS, Tababa EJL, Dimacali CD, Yap-Silva C. Systemic Lupus Erythematosus with Coexistent Psoriasis Vulgaris: a case Report. Acta Medica Philippina 2017; 51: 347-350.

7. Astudillo L, Sailler L, Carreiro M, et al. Psoriasis and systemic lupus erythematosus: a rare association with specific therapeutic problems. Ann Med Interne (Paris) 2003; 154: 3-6.

8. Wang Y, Da G, Yu Y, et al. Coincident systemic lupus erythematosus and psoriasis vulgaris: a case report. G Ital Dermatol Venereol 2015; 150: 749-751.

9. Eichenfield LF, Paller AS, Tom WL, et al. Pediatric psoriasis: Evolving perspectives. Pediatr Dermatol 2018; 35: 170-181, DOI: 10.1111/pde.13382.

10. Kuek A, Hazleman B, Ostör A. Immune-mediated inflammatory diseases (IMIDs) and biologic therapy: a medical revolution. Postgrad Med J 2007; 83: 251-260, DOI: 10.1136/pgmj.2006.052688.

11. Blandizzi C, Gionchetti P, Armuzzi A, et al. The role of tumour necrosis factor in the pathogenesis of immune-mediated diseases. Int J Immunopathol Pharmacol 2014; 27: 1-10.

12. Davidson A, Diamond B. Autoimmune diseases. N Engl J Med 2001; 345: 340-350, DOI: 10.1056/NEJM200108023450506.

13. Agalioti T, Villablanca EJ, Huber S, Gagliani N. Th17 cell plasticity: The role of dendritic cells and molecular mechanisms. J Autoimmun 2018; 87: 50-60, DOI: 10.1016/j.jaut.2017.12.003.

14. Kim N, Thrash B, Menter A. Comorbidities in psoriasis patients. Semin Cutan Med Surg 2010; 29: 10-15, DOI: 10.1016/j.sder. 2010.01.002.

15. Andersen YMF, Wu JJ, Thyssen JP, Egeberg A. Chronologic order of appearance of immune-mediated inflammatory diseases relative to diagnosis of psoriasis. J Am Acad Dermatol 2019; 81: 1283-1291, DOI: 10.1016/j.jaad.2019.04.033.

16. Rizzello F, Olivieri I, Armuzzi A. Multidisciplinary Management of Spondyloarthritis-Related Immune-Mediated Inflammatory Disease. Adv Ther 2018; 35: 545-562, DOI: 10.1007/s12325018-0672-6.

17. Blegvad C, Egeberg A, Tilde E, et al. Autoimmune Disease in Children and Adolescents with Psoriasis: A Cross-sectional Study in Denmark. Acta Dermato-Venereologica 2017; 97: 1225-1229, DOI: 10.2340/00015555-2743.

18. Couture J, Bernatsky S, Scott S, et al. Risk of Childhood Rheumatic and NonRheumatic Autoimmune Diseases in Children Born to Women with Systemic Lupus Erythematosus. Arthritis Rheum 2018; 70: 1796-1800, DOI: 10.1002/art.40570.

19.Zalla MJ, Muller SA. The coexistence of psoriasis with lupus erythematosus and other photosensitive disorders. Acta Derm Venereol Supply (Stockh) 1996; 195: 1-15.

20. Cuesta-Montero L, Belinchón I. Connective tissue diseases and psoriasis. Actas Dermosifiliogr 2011; 102: 487-497, DOI: 10.1016/j.ad.2011.03.002.

21. Wallace DJ, Hahn BH (eds.). Dubois' Lupus Erythematosus and Related Syndromes. W.B. Saunders, Philadelphia 2013. 
22. Shadakshari A, Yu J, Perl A. Association of psoriasis and psoriatic arthritis with systemic lupus erythematosus. 2013 ACR/ ARHP Annual Meeting. October 25-30, 2013, San Diego, CA.

23. O'Leary PA. Chronic lupus disseminatus and psoriasis vulgaris. Arch Dermatol Syphilol 1936; 15: 92.

24. Wang Z, Zhu F, Wang J, et al. Increased CD14+HLA-DR-/low Myeloid-Derived Suppressor Cells Correlate With Disease Severity in Systemic Lupus Erythematosus Patients in an iNOS-Dependent Manner. Front Immunol 2019; 10: 1202, DOI: 10.3389/fimmu.2019.01202.

25. Niu Z, Zhang P, Tong Y. Value of HLA-DR genotype in systemic lupus erythematosus and lupus nephritis: a meta-analysis. Int J Rheum Dis 2015; 18: 17-28, DOI: 10.1111/1756-185X.12528.

26. Hahn BH. The pathogenesis of SLE. In: Wallace DJ, Hahn B (eds.). Dubois' Lupus Erythematosus and Related Syndromes. Elsevier Saunders, Philadelphia 2010: 25-34.

27. Pisetsky DS. The Complex Role of DNA, Histones and HMGB1 in the Pathogenesis of SLE. Autoimmunity 2014; 47: 487-493, DOI: 10.3109/08916934.2014.921811.

28. Costner MI, Grau RH. Update on connective tissue diseases in dermatology. Semin Cutan Med Surg 2006; 25: 207-220, DOI: 10.1016/j.sder.2006.08.004.

29. Owczarczyk-Saczonek A, Placek W. Łuszczyca jako choroba autoimmunologiczna [Psoriasis as an autoimmune disease]. Prz Dermatol 2014; 101: 278-287.

30. Sin CZ, Wang TS, Chiu HY, Tsai TF. Human leukocyte antigen and demographic characteristics in Chinese patients with active peripheral type psoriatic arthritis who had inadequate response to conventional disease-modifying antirheumatic drugs in a single dermatologic clinic. PloS One 2019; 14: e0210076, DOI: 10.1371/journal.pone.0210076.
31. Minh VN, Thi VB, Van TC, et al. The Relationship between HLA-B27, HLA-Cw06, HLA-DR7 and Psoriatic Arthritis in Vietnamese Patients: Disease Progression and Therapeutic Burden. Open Access Maced J Med Sci 2019; 7: 300-301, DOI: 10.3889/oamjms.2019.064.

32. Furue $M$, Kadono T. The contribution of IL-17 to the development of autoimmunity in psoriasis. Innate Immun 2019; 25: 337-343, DOI: 10.1177/1753425919852156.

33. Wolska H, Błaszczyk M, Jabłońska S. Phototests in patients with various forms of lupus erythematosus. Int J Dermatol 1989; 28: 98-103, DOI: 10.1111/j.1365-4362.1989.tb01327.x.

34. Seminario-Vidal L, Hughey LS. Hydroxychloroquine de NovoInduced Psoriasis in a Patient with Lichen Planus Pigmentosus. Skinmed 2015; 13: 492-494.

35. Williams EL, Gadola S, Edwards CJ. Anti-TNF-induced lupus. Rheumatology (Oxford) 2009; 48: 716-720, DOI: 10.1093/rheumatology/kep080.

36. Tierney E, Kirthi S, Ramsay B, Ahmad K. Ustekinumab-induced subacute cutaneous lupus. JAAD Case Rep 2019; 5: 271-273, DOI: 10.1016/j.jdcr.2019.01.015.

37. Varada S, Gottlieb AB, Merola JF, et el. Treatment of coexistent psoriasis and lupus erythematosus. J Am Acad Dermatol 2015; 72: 253-260, DOI: 10.1016/j.jaad.2014.10.038. 